\title{
Fracture toughness to understand stretch-flangeability and edge cracking resistance in AHSS
}

\author{
D. Casellas ${ }^{1,3}$, A. Lara ${ }^{1}$, D. Frómeta ${ }^{1}$, D. Gutiérrez ${ }^{1}$, S. Molas ${ }^{1}$, Ll.Pérez ${ }^{1}$, J. Rehrl ${ }^{2}$ and \\ C. Suppan $^{2}$ \\ ${ }^{1}$ Fundació CTM Centre Tecnològic, Plaça de la Ciència 2, 08243 Manresa, Spain \\ ${ }^{2}$ voestalpine Stahl GmbH, voestalpine-Straße 3, 4020 Linz, Austria \\ ${ }^{3}$ Luleå University of Technology, 97187 Luleå, Sweden
}

Corresponding author: daniel.casellas@ctm.com.es

\section{Abstract}

1 The edge fracture is considered as a high risk for automotive parts, especially for parts made of

2 Advanced High Strength Steels (AHSS). The limited ductility of AHSS makes them more sensitive to the edge damage. The traditional approaches, such as those based on ductility measurements or forming limit diagrams, are unable to predict this type of fractures. Thus, stretch-flangeability has become an important formability parameter in addition to tensile and

6 formability properties. The damage induced in sheared edges in AHSS parts affects stretchflangeability, because the generated microcracks propagates from the edge. Accordingly, a fracture mechanics approach may be followed to characterize the crack propagation resistance.

With this aim, this work addresses the applicability of fracture toughness as a tool to understand crack-related problems, as stretch-flangeability and edge cracking, in different AHSS grades. Fracture toughness was determined by following the essential work of fracture methodology and stretch-flangeability was characterized by means of hole expansions tests. Results show a good correlation between stretch-flangeability and fracture toughness. It allows postulating fracture toughness, measured by the essential work of fracture methodology, as a key material property to rationalize crack propagation phenomena in AHSS.

16

17 Key words: Stretch-flangeability, AHSS, Essential Work of Fracture, fracture toughness. 


\section{INTRODUCTION}

19 Cutting or shearing operations are widely used in metal sheet forming industries to produce final components. It is well known that cut or sheared edges may present damage in terms of surface irregularities, microvoids and microcracks. The degree of such damage at the cut edge is known as edge integrity. It is known to influence part quality in materials with limited ductility when sheared edges are subjected to bending or stretching in subsequent forming operations. This is the case for the so-called AHSS (Advanced High Strength Steels) that are extensively implemented in the automotive industry to reduce weight and increase crashworthiness (a modern vehicle body contains about 30-50 \% of AHSS [1]).

Although AHSS have contributed to the huge improvement of today's vehicles, they have also introduced new challenges which are still only solved partially. In the last years, many works focused on springback and formability prediction of these steels [2-6]. However, less attention has been given to the cracking phenomena observed for some AHSS grades at cut or sheared edges (Figure 1). Edge cracking is associated with sheared areas that expands during forming operations involving stretch flanging or hole expansion. This process increases the flange edge length during the deformation [7]. Typical examples of stretch flanges in the automotive industry include cut-outs in automotive inner panels and corners of window panels, hub-holes of wheel discs, hidden joints, etc. Edge cracking compromises part quality and it is a serious production problem, because if it is not accounted for in the overall design, the load paths through the vehicle frame in a crash situation can be misdirected and the resultant intrusion levels can exceed target levels. Such problem was not observed in mild steels, whose high ductility prevents the cut edge from cracking, and less knowledge and expertise is available to immediately solve it in industrial parts [8,9]. 
AHSS are more sensitive to the crack edge integrity, so their crack edge resistance depends on the hole preparation method (punching, laser cutting waterjet cutting...), as well as on the steel microstructure to tolerate the induced damage [10-12]. Hence, the edge fracture can be considered as a high risk for AHSS automotive components. The traditional approaches, such as the Forming Limit Diagram (FLD), are unable to predict this type of fracture and great efforts have been made to develop failure criteria that could predict edge fracture [9]. In this sense, stretch-flangeability has become a particularly important formability parameter in addition to tensile properties, especially for parts under heavy deformation conditions, to rationalize edge cracking problems.

The stretch-flangeability in low C Steels and AHSS has been studied well, but the results obtained in some AHSS grades were initially surprising, since stretch-flangeability increases when the material strength also increases and ductility diminishes $[6,11,13]$. This observation is in the opposite way of the thinking for ductile steels, where it is accepted that ductility improves flangeability. In dual-phase steels this behavior is explained by the hardness difference between ferrite and martensite [14-16]. On the other hand, the works of Fonstein et al. [17] and Takahashi et al. [18] approached the problem from a fracture mechanics point of view and proposed that fracture toughness can be used to rationalize the observed behavior for AHSS. However, this approach is not intensively applied to metal sheets yet because fracture toughness cannot be readily measured by standard characterization techniques. It means that fracture or crack propagation phenomena in metal sheets, as the observed behavior in stretchflangeability tests, cannot be rationalized in terms of intrinsic mechanical properties, which hampers process and material optimization. Aimed at filling this gap of knowledge, the objective of the present work is to measure and use fracture toughness as a tool to understand crack-related problems in AHSS sheets, as stretch-flangeability or edge cracking resistance. 


\subsection{Materials}

Different AHSS grades were studied: (a) two commercially available cold forming grades, a dual phase steel (DP1000) and a complex phase steel (CP1000); (b) three $3^{\text {rd }}$ generation AHSS grades: TBF (Trip-aided Bainitic ferrite) steel, Q\&P (Quenching \& partitioning) steel , and mixed TBF/Q\&P microstructure; (c) two microstructures of hot stamped boron steel: one inpress hardened condition, named as PHS1500 and another one with an additional tempering treatment, named as PHS1000.

Table I shows the chemical composition of the investigated steels. Microstructure of these steel grades has been studied by means of scanning electron microscopy (SEM) after electropolishing. The corresponding microstructures can be seen in Figures 2 to 4 . CP-like grades (CP1000 and mixed TBF/Q\&P) as well as the Q\&P grade show a homogeneous matrix of bainite/tempered martensite. $\mathrm{Q} \& \mathrm{P}$ and mixed $\mathrm{TBF} / \mathrm{Q} \& \mathrm{P}$ also contain retained austenite. In DP1000 and TBF grades the matrix consists of a mixture of ferrite, bainitic ferrite, bainite/tempered martensite, martensite and retained austenite. PHS1500 consists of a homogeneous martensitic matrix, which is slightly auto-tempered during cooling. The tempering treatment for PHS1000 basically leads to relaxation of the tetragonal martensite lattice by formation of carbides, which can be observed as white lines and spots in Figure $4 \mathrm{~b}$.

\subsection{Tensile Tests}

Conventional axial tensile tests were performed according to EN-ISO6892-1 with the specimens oriented transversally to the rolling direction. Table II shows the results.

\subsection{Hole Expansion Test}

Looking at stretch-flangeability, the hole expansion test (HET) closely resembles the process under production conditions to form such flanges starting with punched holes. This is the most 
used method to evaluate the suitability of the sheet steel for forming such "flanges". The value obtained in this test is the Hole Expansion Ratio (HER), which is calculated using the initial hole diameter $\left(\mathrm{D}_{0}\right)$ and the diameter at first through thickness crack apparition $\left(\mathrm{D}_{\mathrm{h}}\right)$ as follows:

$$
\operatorname{HER}[\%] \text { or } \lambda=\left[\frac{D_{h}-D_{0}}{D_{0}}\right] \cdot 100
$$

HER indicates the maximum diametrical expansion that a circular punched hole can reach when a conical tool is forced into it until a crack in the hole edge extends through the full sheet thickness. The HET were carried out in a universal testing machine using a conical punch with an angle of $60^{\circ}$ according to ISO16630 standard [19]. The initial hole diameter was $10 \mathrm{~mm}$ and the driving speed of the conical punch was $1 \mathrm{~mm} / \mathrm{s}$. The punching clearance was set to $12 \%$, because it is following standard recommendations and previous work where it is experimentally assessed that this value gives rise to the maximum HER in AHSS [11]. The followed punching and flanging processes are shown in Figure 5. Three samples of 100 x $100 \mathrm{~mm}$ from each steel were tested. A clamping force of $50 \mathrm{KN}$ was applied to the test piece to prevent any material draw-in from the clamping area during the test. During the HET the emerging and extension of cracks were detected by a digital image correlation equipment (DIC) located below the tool. $D_{h}$ was measured from the image at which the first through-thickness crack was observed, before remove the punch.

\subsection{Measurement of fracture toughness in thin sheets}

In fracture mechanics, the fracture toughness is defined as the energy spent in the creation of two surfaces at the crack tip that give rise to crack propagation. For ductile materials experimental approaches based on elastic-plastic fracture mechanics allow determining the crack propagation resistance, as the $\mathrm{J}$-integral (giving the value of $\mathrm{J}_{\mathrm{C}}$ ), the $\mathrm{J}-\mathrm{R}$ curve or the CTOD measurement. The experimental complexity of standardized methods and the difficulty for transferring the obtained values to thin sheet components have given rise to a lack of knowledge regarding toughness of metal sheets. As a consequence, the fracture toughness of 
the AHSS sheets is not known. For thin plates an alternative method to characterize fracture toughness was developed in the 80s; the EWF (Essential Work of Fracture) methodology. It was successfully applied to characterize ductile alloys, and the obtained toughness value was found to be equivalent to $\mathrm{J}_{\mathrm{C}}$ by many authors [20-27]. Nowadays it is commonly applied to

120 characterize polymeric thin films following a protocol developed by the ESIS (European 121 Structural Integrity Society), but it is not extensively used for thin steel sheets. Recent works 122 show that the EWF methodology can be applied to AHSS sheets [27-31].

The EWF is experimentally evaluated by following the methodology developed by Cotterell and Reddel [20]. These authors proposed that the total work of fracture $\left(W_{f}\right)$ during the ductile fracture can be separated into two components: i) The essential work of fracture $\left(W_{e}\right)$ spent in the fracture process zone (FPZ) in front of the crack tip, and ii) non-essential plastic work $\left(W_{p}\right)$ dissipated in an outer region as a consequence of plastic deformation. Double Edge Notched Tensile (DENT) specimen (Figure 6) is particularly suitable for fracture mechanics tests

130 because the transverse stress between the notches is tensile and there is no buckling. In DENT 131 specimens if the material in front of the crack tip of the two notches, the ligament, is completely 132 yielded and the plastic zone is confined to the notched ligament, then the plastic work performed 133 for total fracture is proportional to the plastic volume at crack imitation and the work performed 134 at the FPZ is proportional to the fractured area. It can be expressed as:

$$
W_{f}=W_{e}+W_{p}=w_{e} l t+w_{p} \beta l^{2} t
$$

136 Where $\beta$ is a shape factor that depends on the shape of the plastic zone, $t$ is the sheet thickness 137 and $l$ is the ligament length between the two notches. The specific work of fracture $\left(w_{f}\right)$ is 138 obtained by dividing equation (2) by the initial ligament area $l t$. Thus, equation (2) can be 139 rewritten as: 


$$
\frac{w_{f}}{l t}=w_{f}=w_{e}+w_{p} \beta l
$$

143 If $w_{f}$ is plotted against the ligament length $l$, a straight line with a positive intercept, which is

144 the specific essential work of fracture $\left(w_{e}\right)$, is obtained.

145 When applying the EWF methodology to metal sheets it should be kept in mind that the 146 obtained values of $w_{e}$ are greatly affected by the notch root radius. Such effect has been 147 experimentally demonstrated in mild and dual-phase steels [30, 31]. The effect of the notch root

148 radius on the fracture toughness measurement is well known in plain strain fracture toughness 149 tests, below a critical notch root radius value the fracture toughness measurements are 150 independent of the notch radius and fracture toughness is considered as a material intrinsic 151 property. To avoid the effect of notch root radius, the ASTM E399 procedure for evaluating the

152 fracture toughness suggests the nucleation of a fatigue crack at the notch root. This fatigue crack

153 has the lowest possible radius at the crack tip, ensuring valid fracture toughness values.

154 Similarly, in the EWF methodology, notches with the lowest possible root radius must be used

155 (Figure 6). However, $w_{e}$ is not fully a material intrinsic property because it is influenced by 156 necking of the fracture process zone and this in turn depends on the thickness of the sheet 157 material.

159 In the present work $W_{f}$ was measured by loading DENT specimens of 240x55 mm, extracted 160 transversally to the sheet rolling direction, in a universal testing machine with a speed of 1

$161 \mathrm{~mm} / \mathrm{min}$. The displacement was measured with a video extensometer with gauge length of 50 $162 \mathrm{~mm}$. Specimens ligaments length ranges from $6 \mathrm{~mm}$ to $16 \mathrm{~mm}$. About 3 to 5 specimens were 163 tested up to fracture for each ligament length. The plot of $w_{f}$ against $l$ gives the values of $w_{e}$, as 164 detailed before. Linear fitting was performed using a confidence interval of $95 \%$. 


\section{RESULTS}

\subsection{Hole Expansion Test}

167 Figure 7 shows the measured HER values. They are similar to previously reported results for other AHSS, as DP780, DP980 and press hardened steels [6]. They are also considerably lower than those obtained with mild steels, where HER ranges from 100 to $140 \%$ [6, 30, 32]. HER values show relatively large scatter, as has been reported by other authors in AHSS [6, 33].

171 Figure 8 shows pictures of the first crack extension around the flange in DP1000 and CP1000

172 steels determined with the DIC technique. From figure 8 the poor hole expansion of DP1000

173 before the first crack extension can be seen, whilst CP1000 steel presents a much greater hole expansion capacity than the DP steel. As expected CP-like microstructures as those in CP, Q\&P, PHS1000 and TBF/Q\&P show high HER values, meanwhile DP-like microstructures, as DP and TBF, show low HER values. It is in agreement with previous works on multiphase steels,

177 containing mixtures of ferrite, bainite and martensite, as CP and DP. In such steels the combination of a soft phase, ferrite, with a hard phase, martensite or bainite, give rise to high strain hardening coefficients and large ductility. Damage in DP and CP steels is related to the hardness difference between phases. Strain localizes in ferrite and promotes void generation at

181 the ferrite/martensite interface. Thus, finer microstructures as well as replacement of martensite

182 by bainite give rise to higher damage resistant microstructures and show higher HER values

183 [15-18]. PHS1500 presents the lowest HER values because the microstructure is martensite, with lower damage resistance than DP and CP ones.

\subsection{Essential Work of Fracture}

186 The definition of the EWF methodology imposes that the crack tip must be yielded before the

187 onset of crack propagation. In DENT specimens it means that the material between the two 
notches must be fully yielded. This constraint is satisfied in mild steels [26], but the higher yield strength of AHSS implies that this condition must be verified for the studied AHSS. DIC analysis was performed for all the steels studied and showed that at maximum load in samples with the largest ligament length, the ligament area is fully yielded and that the plastic zone

192 morphology is almost circular. Both requirements must be fulfilled to obtain valid values of $w_{e}$

193 from equation (3). Figure 9 shows DIC analysis on the shortest and largest ligament for DP1000

194 and PHS15000. The measured values of $w_{e}$ are shown in Figure 10.

196 Similarly to the HER results, a relationship between microstructure and toughness can be seen;

197 CP-like grades (CP1000, TBF/Q\&P and Q\&P grades) show higher EWF values than DP-type 198 steels (DP1000 and TBF). PHS1500 presents also one of the lowest toughness values, a value 199 which increases significantly after the tempering treatment done at PHS1000.

\section{DISCUSSION}

Figure 11a shows the relationship between HER and tensile strength for the studied steels, together with results for mild steels and other AHSS grades extracted from reference 6 . Results

204 for mild steel and AHSS with tensile strength lower than 800MPa show an almost linear correlation between HER and tensile strength and elongation, so HER linearly decreases when tensile strength increases. When HER values are plotted against elongation, the opposite trend is observed (Figure 11b). However, such relationships are not followed by the here investigated

208 AHSS grades, with tensile strength above $800 \mathrm{MPa}$. This experimental behavior is in agreement 209 with previous works for AHSS, where it is stated that ductility or elongation cannot be used to rationalize stretch flangeability in AHSS [13, 14, 34, 35]. 
212 Stretch flangeability is dictated by the propagation of cracks through the material thickness,

213 thus the HET values could be related to the material resistance to crack propagation, which is

214 the fracture toughness. Fonstein et al. [17] and Takahashi et al. [18] also stated that stretch-

215 flangeability is controlled by the propagation of cracks or defects introduced during hole cutting

216 and showed that tougher materials (measured in terms of $\mathrm{J}_{\mathrm{IC}}$ ) give rise to higher HER values.

217 Aimed at proving such correlation, the results of EWF have been used to rationalize the HER

218 values in the current work. It is shown in Figure 12. The experimental values of HER and $w_{e}$

219 correlate very well and fits an almost linear relationship, i.e. the tougher materials present

220 higher HER values, whilst lower HER ones are associated with lower we. Accordingly, fracture

221 toughness of AHSS sheets, in terms of $w_{e}$, can be used to properly rationalize stretch-

222 flangeability in AHSS. These results allow to postulate that fracture toughness becomes a

223 relevant material property when designing AHSS with improved crack edge resistance.

\section{CONCLUSIONS}

Based on the experimental results of stretch-flangeability and fracture toughness measurements performed by means of the EWF methodology for several grades of AHSS with high tensile strength, the following conclusions can be drawn:

229 - The EWF methodology can be applied to AHSS sheets with very high tensile strength, up to $1500 \mathrm{MPa}$, to estimate fracture toughness.

231 - Classical mechanical properties, such as ultimate tensile strength and elongation, are unable to predict HER in AHSS with high tensile strength (above 800MPa).

$233 \quad$ - The values of fracture toughness, in terms of $w_{e}$, show the same trend as stretchflangeability for the investigated steels.

235 - Fracture toughness is the material property to rationalize the observed improvement 
toughness may help to understand the cracking related phenomena in AHSS, as edge cracking.

239 


\section{ACKNOWLEDGEMENTS}

This investigation has been partially funded by the Catalan government under grant TECCTA13-1-0005 and by the European Commission, Research Fund for Coal and Steel, under grant agreement RFSR-CT-2014-00015 (Tough-Sheet).

\section{REFERENCES}

[1] N. Lutsey: Report UCD-ITS-RR-10-10. Davis, CA: Institute of Transportation Studies, University of California, 2010.

[2] P.Chen, M. Koç: J. Mat. Proc. Tech., 2007, vol. 190, pp. 189-198.

[3] P. Tsipouridis, E. Werner, C. Krempaszky, E. Trag: Steel Res. Int., 2006, vol. 77, pp. 654667.

[4] P. J. Jacques: Current Opinion in Solid State and Material Science, 2004, vol. 8, pp. 259265.

[5] A. Karelova, C. Krempaszky, M. Dünckelmeyer, E. Werner, T. Hebesberger, A. Pichler: Mat. Sci. \&Tech. (MS\&T), 2009, pp. 1358-1368.

[6] X. Chen, H. Jiang, Z. Cui, C. Lian, C. Lu: Proc. Eng., 2014, vol. 81, pp. 718-723.

[7] V. Uthaisangsuk, U. Prahl, W. Bleck: Comp. Mat. Sci., 2009, pp. 617-623.

[8] X. Wu, H. Bahmanpour, K. Schmid: J. Mat. Proc. Tech., 2012, vol. 212, pp. 1209-1224.

[9] M. Luo, T. Wierzbicki: Int. J. of Solids and Struct., 2010, vol. 47, pp. 3084-3102.

[10] D.J. Thomas: J. Fail. Anal. and Preven., 2013, vol. 13(4), pp. 451-462.

[11] D. Gutiérrez, J. Escaler, A. Lara, D. Casellas, J.M. Prado: Proceedings of the IDDRG2011.

[12] K. Watanabe, M. Tachibana, K. Koyanagi, K. Motomura: LS-Dyna Conference, 2006.

[13] P. Larour, H. Pauli, J. Freudenthaler, A. Grünsteidl: Proceedings of the IDDRG2011.

[14] X. Fang, Z. Fan, B. Ralph, P. Evans, R. Underhill: J. of Mat. Sci., 2003, vol. 38, pp. 38773882. 
[15] K. Hasegawa, K Kawamura, T. Urabe, Y. Hosoya: ISIJ International, 2004, pp. 603-609.

[16] G. Avramovic-Cingaraa, Y. Ososkova, M.K. Jain, D.S. Wilkinson: Mat. Sci \& Eng. A, 2009, vol. A516, pp. 7-16.

[17] N. Fonstein, H-J. Jun, G. Huang, S. Sriram, B. Yan: Mat. Sci. and Tech. 2011, pp. 634641.

[18] Y. Takahashi, O. Kawanom, K. Ushiodam, S. Aihara: Asia Steel Int. Conference, 2012.

[19] ISO/TS16630. Metallic materials - Method of hole expanding test, 2003.

[20] B. Cotterell, J.K. Reddel: Int. J. Fracture, 1977, pp. 267-277.

[21] Y.W. Mai, P. Powell: J. Polym. Sci., 1991, vol. 29, pp. 785-793.

[22] B. Cotterell, A. G. Atkins: Int. J. Fract., 1996, vol. 81, pp. 357-372.

[23] J. Wu, Y.W. Mai: Pol. Eng. and Sci., 1996, vol. 36, pp. 2275 - 2288.

[24] Y. Marchal, K. Schmidt, T. Pardoen, R. Knockaert. I. Doghri: ECF 11. Mechanisms and Mechanics of Damage and Failure, 1996, pp. 2259-2265.

[25] T. Pardoen, Y. Marchal, F. Delannay: J. Mech. Phys. Sol., 1999, vol. 47, pp. 2093-2123.

[26] T. Pardoen, F. Hachez, B. Marchioni, P.H. Blyth, A.G. Atkins: J. of Mec. and Physics of Solids, 2004, vol. 52, pp. 423-452.

[27] G. Lacroix, T. Pardoen, P.J. Jacques: Act. Mat., 2008, vol. 56, pp. 3900-3913.

[28] R. Muñoz, A. Lara, D. Casellas: Proceedings of the IDDRG2011 International Conference, 2011.

[29] D. Gutiérrez, Ll. Pérez, A. Lara, D. Casellas, J.M. Prado: 19th European Conference on Fracture (ECF19), 2012.

[30] O. Akourri, M. Louah, A. Kifani, G. Gilbert, G. Pluvinage: Eng. Fract. Mech., 2000, pp. 491-505.

[31] D. Gutiérrez, Ll. Pérez, A. Lara, D. Casellas, J.M. Prado: Revista de Metalurgia, 2013, vol. 49 , no. 1 , pp. $45-54$. 
[32] K. Mori, Y. Abe, Y. Suzui: J. Mat. Proc. Tech., 2010, vol. 210, pp. 653-659.

[33] P. Larour, J. Freudenthaler, A. Grünsteidl, K.Wang: Proceedings of the IDDRG2014.

[34] M. Kapp: PhD Thesis. Erich Schmid Institute of Materials Science, 2011.

[35] H. Mohrbacher: Adv. in Manuf., 2013, vol. 1, pp. 28-41.

\section{TABLES}

Table I. Chemical composition, in weight \%.

\begin{tabular}{|c|c|c|c|c|c|c|}
\hline Steel grade & $\mathrm{C}$ & $\mathrm{Si}$ & Mn & $\mathrm{Cr}$ & B & $A l$ \\
\hline CP1000 & $\sim 0,1$ & & & & & \\
\hline DP1000 & $\sim 0,15$ & & & & & \\
\hline TBF & $\sim 0,2$ & & & & $<0,003$ & \\
\hline Q\&P & $\sim 0,1$ & $0,5-1,0$ & $2,2-2,6$ & $<0,7$ & & - \\
\hline TBF/Q\&P & $\sim 0,1$ & & & & & \\
\hline \begin{tabular}{|l|} 
PHS1500 \\
PHS1000
\end{tabular} & $\sim 0,2$ & $\sim 0,2$ & $\sim 1,2$ & & $\sim 0,003$ & \\
\hline
\end{tabular}

Table II. Mechanical properties: yield strength (YS), ultimate tensile strength (UTS), Total elongation and hardening exponent (n). Thickness $(t)$ for all grades is also given.

\begin{tabular}{cccccc}
\hline Steel grade & $\mathbf{t}[\mathbf{m m}]$ & $\begin{array}{c}\text { YS } \\
{[\mathbf{M P a}]}\end{array}$ & $\begin{array}{c}\text { UTS } \\
{[\mathbf{M P a}]}\end{array}$ & $\begin{array}{c}\text { Elongation } \\
{[\%]}\end{array}$ & $\mathbf{n}$ \\
\hline CP1000 & 1,4 & 920 & 1008 & 8.8 & 0.05 \\
\hline DP1000 & 1,4 & 738 & 1027 & 10.3 & 0.10 \\
\hline TBF & 1,5 & 725 & 1019 & 14.7 & 0.12 \\
\hline Q\&P & 1,4 & 909 & 1209 & 7.4 & 0.09 \\
\hline TBF/Q\&P & 1,4 & 876 & 1026 & 11.3 & 0.09 \\
\hline PHS1500 & 1,5 & 1075 & 1552 & 5.2 & 0.08 \\
\hline PHS1000 & 1,5 & 988 & 1007 & 7.3 & 0.05 \\
\hline
\end{tabular}




\section{FIGURE CAPTIONS}

Figure 1. Cracks produced in cold formed AHSS automotive parts.

Figure 2. Microstructure of: (a) CP1000 steel and (b) DP1000 steel.

Figure 3. Microstructure of $3^{\text {rd }}$ generation AHSS: (a) TBF, (b) Q\&P and (c) TBF/Q\&P grade.

Figure 4. Microstructure of press hardened steels: (a) PHS1500, (b) PHS1000.

Figure 5. Hole punching and hole expansion procedure followed in this work according to ISO16630 [19].

Figure 6. Double Edge-Notched specimen (DENT) indicating the fracture and plastic zone.

Figure 7. HER values of the investigated steels, together with reported results for other AHSS [6].

Figure 8. First crack extension in the hole edge of CP1000 and DP1000 steels (orange arrows).

Figure 9. Strain analysis on DP1000 and PHS1500. At maximum load the ligament area is fully yielded. DIC images show in red the material area over the yield stress.

Figure 10. $w_{e}$ values obtained from the investigated steels

Figure 11. Correlation between HER and mechanical properties of AHSS and new generation steels, together with published data for mild steel and AHSS [6].

Figure 12. Correlation between HER and EWF of AHSS and new generation steels. 